\title{
Liquefying-damage of mine tailings dams in earthquakes
}

\author{
Sijing Cai University of Science and Technology Beijing, China \\ Xiaoning Wang University of Science and Technology Beijing, China \\ Wensheng Lyu University of Science and Technology Beijing, China \\ Peng Yang Beijing Union University, China
}

\begin{abstract}
Tailings dams with severe damage from earthquakes could possibly pose a danger to the safety of mine production, the livelihood of local people, and the quality of the local environment. For instance, the "5.12" violent earthquake happened in 2008 in the Wenchuan county, Sichuan province, China, caused severe liquefaction and damage to nine ordinary tailings dams. This paper chose one of the nine damaged tailings dams and conducted laboratory tests into the static and dynamic properties of tailings dam materials. $A$ mechanical model considering seismic load acting on tailings dam as well as the main factors influencing the stability of tailings dam under seismic action were proposed. By comparing the simulated data derived from ANSYS software with the field measured data, some key areas of tailings dam that can be easily liquefied and damaged in earthquake were identified. Furthermore, a number of parameters in controlling the factors of safety of tailings dams in earthquakes were also studied in detail. Therefore, for the safety of tailings disposal in the mines located in areas frequent struck by earthquakes, paste tailings disposal would be a reasonable choice.
\end{abstract}

\section{Introduction}

The process of mining inevitably leads to one or several tailing dams around a mine. However, these tailing dams with severe damage from earthquakes could possibly pose a danger to the safety of mine production, the livelihood of local people, and the quality of the local environment. For example, the "5.12" violent earthquake $\left(\mathrm{M}_{\mathrm{w}}=8.3\right)$ happened in 2008 in the Wenchuan county, Sichuan province, China, caused severe liquefaction and damage to nine ordinary tailings dams (Zhang et al., 2010).

With their construction materials being relatively loose and in granule shape and tailings pulp piped from the mine mill featuring a high percentage of water, the dam materials could be easily liquefied under dynamic loading of violent earthquakes. Furthermore, a number of longitudinal and sectional cracks would occur in the dam body during earthquakes. Hence, liquefying-damage is a typical destruction of mine tailings dams in earthquakes (Franks and Boger, 2011; Wang et al., 2012; Zhang et al., 2012; Pu and Zhang, 2012; Zhang et al., 2002; Robertson and Wride, 1998).

In order to understand the safety requirements of tailings dams under dynamic loading of earthquakes, this paper chose one of the nine damaged tailings dams in Wenchuan Earthquake and carried out a series of research, including tailings dam field investigation, theoretical analysis, laboratory tests of tailings dam materials and numerical modeling using the ANSYS software. 


\section{$2 \quad$ Methodology}

\subsection{Assessment model of tailings dam liquefaction}

To study the liquefying-damage process of tailings dams in earthquakes, the cyclic stress method was developed from the empirical evaluations of in suit observation and laboratory test data. In order to establish the method, the first procedure is to estimate and determine the cyclic resistance ratio (CRR), the capacity of tailings dam layers to resist liquefaction, by theoretical analysis and laboratory tests. The evaluating methods of CRR include the standard penetration test (SPT), the cone penetration test (CPT), the Becker hammer test (BPT), and the shear wave velocity $\left(\mathrm{V}_{\mathrm{s}}\right)$ measurement; the second procedure is to evaluate the cyclic shear stress ratio (CSR) induced by the earthquake ground motions and to present the cyclic loading on the tailings dam; the third procedure is to assess the safety of the tailing dam under earthquake load, by calculating the factors of safety (FS) with the values of CRR and CSR.

The FS of tailings dams against liquefaction is expressed as:

$$
\mathrm{FS}=\frac{C R R}{(C S R)_{M_{W}}}
$$

Where:

$$
\begin{aligned}
C R R= & \text { the equivalent uniform shear stress induced by an earthquake having a moment } \\
& \text { magnitude, } \mathrm{M}=M_{w} ; \\
C R R \quad= & \text { the cyclic resistance ratio; }
\end{aligned}
$$

At positions where the loading exceeds the resistance (i.e. FS $<1$ ), liquefaction is expected to occur. The calculations of CRR and CSR are crucial for the assessment of tailings dams' safety in earthquakes.

\subsubsection{Cyclic stress ratio (CSR)}

The induced cyclic stress ratio $(C S R)$ is calculated by the following equation:

$$
(C S R)_{M_{w}}=0.65\left(\frac{\sigma_{v} a_{\max }}{\sigma_{v}^{\prime}}\right) \frac{\gamma_{d}}{M S F} \frac{1}{K_{\sigma}}
$$

Where:

$$
\begin{array}{ll}
a_{\max } & =\text { the peak horizontal acceleration at the ground surface generated by earthquake; } \\
\sigma_{v} & =\text { the total overburden pressure; } \\
\sigma_{v}^{\prime} & =\text { the effective overburden pressure; } \\
\gamma_{d} & =\text { the stress reduction coefficient that measures the attenuation of peak shear stress with } \\
& \quad \text { depth due to the non-eplastic behavior of tailings; } \\
M S F & =\text { the magnitude scaling factor; } \\
K_{\sigma} & =\text { the correction factor for overburden pressure; }
\end{array}
$$

(1) Stress reduction coefficient, $\gamma_{d}$

The stress reduction coefficient $\gamma_{d}$ describes the ratio of cyclic stresses for a flexible tailings column to the cyclic stresses for a rigid tailings column, and $\gamma_{d}$ can be calculated by the following equations (3a and $3 \mathrm{~b}$ ):

$$
\ln \left(\gamma_{d}\right)=-1.012-1.126 \sin \left(\frac{z}{11.73}+5.133\right)+\left[0.106+0.118 \sin \left(\frac{z}{11.28}+5.142\right)\right] M_{w}
$$

Where: 
This equation is applicable to a depth $z \leq 34 \mathrm{~m}$, while the following expression is applicable for $\mathrm{z}>34 \mathrm{~m}$ :

$$
\gamma_{d}=0.12 \exp \left(0.22 M_{w}\right)
$$

(2) Magnitude scaling factor, $M S F$

The magnitude scaling factor $(M S F)$ is usually defined as:

$$
M S F=\frac{\operatorname{CSR}_{M_{w}}}{\operatorname{CSR}_{M_{w}=7.5}}
$$

From Equation (4), MSF is used to adjust $C S R$ in accordance with the earthquake magnitude $M_{w}$. Therefore, $M S F$ is an approximately modified coefficient of the effects of durative shaking or equivalent number of stress cycles. Earthquake magnitude and the number of uniform stress cycles are used to calculate the values of magnitude scaling factor:

$$
M S F=6.9 \exp \left(\frac{-M_{w}}{4}\right)-0.058
$$

(3) Overburden pressure correction factor, $K_{\sigma}$

The overburden pressure correction factor is expressed by:

$$
K_{\sigma}=1-\frac{1}{18.9-2.55 \sqrt{\left(N_{1}\right)_{60}}} \ln \left(\frac{\sigma_{v}^{\prime}}{P_{a}}\right) \leq 1
$$

Where:

$$
\begin{aligned}
& P_{a} \quad=\text { the atmospheric pressure taken as } 100 \mathrm{kPa} \text {; } \\
& \left(N_{1}\right)_{60}=\text { the corrected SPT }-\mathrm{N} \text { value }=C_{N} N_{60} ; \\
& N_{60}=\text { the } N \text { value corrected for the field procedures and to an average energy ratio of } 60 \% \\
& \text { of the SPT hammer; } \\
& C_{N}=\text { the correction factor for over burden pressure, calculated by: } \\
& C_{N}=\left(\frac{P_{a}}{\sigma_{v}^{\prime}}\right)^{0.784-0.0768 \sqrt{\left(N_{1}\right)_{60}}} \leq 1.7
\end{aligned}
$$

\subsubsection{Cyclic resistance ratio (CRR)}

CRR is commonly calculated by means of parameters measured in field tests (standard penetration tests):

$$
\mathrm{CRR}=\exp \left[\frac{\left(N_{1}\right)_{60 c s}}{14.1}+\left(\frac{\left(N_{1}\right)_{60 c s}}{126}\right)^{2}-\left(\frac{\left(N_{1}\right)_{60 c s}}{23.6}\right)^{3}+\left(\frac{\left(N_{1}\right)_{60 c s}}{25.4}\right)^{4}\right]-2.8
$$

Where:

$\left(N_{1}\right)_{60 c s}=$ the SPT $-\mathrm{N}$ value adjusted to an equivalent clean sand value, calculated by the following equation:

$$
\left(N_{1}\right)_{60 c s}=\left(N_{1}\right)_{60}+\exp \left[1.63+\frac{9.7}{F C+0.1}-\left(\frac{15.7}{F C+0.1}\right)^{2}\right]
$$

Where:

FC $=$ the percentage of fine particle $(\leq 25 \mu \mathrm{m})$ content for tailings lack cohesion; The above equations show clear interdependency between $\left(N_{1}\right)_{60}$ and $C_{N}$. Overall, the assessment model is conducive to calculating the factors of safety (FC) and to estimating the liquefying risks of tailing dams under the dynamic load of earthquakes.

\subsection{Laboratory tests of tailings dam materials}

In order to examine the material properties of the tailings dams severely damaged in the 2008 Wenchuan 
Earthquake, specimens of tailings materials were taken from one of the damaged tailings dams, with static and dynamic tests carried out using a 3-axial dynamic testing machine. The dynamic testing arrangement is listed in Table 1.

Table 1 Tests of tailings dynamic properties

\begin{tabular}{cccc}
\hline Tested materials & Testing type & Confined stress (kPa) & Vibration (times) \\
\hline \multirow{2}{*}{ Fine tailings } & Dynamic strength & 100,200 & $8,12,20,30$ \\
& Dynamic modulus & 100,200 & 5 \\
\hline
\end{tabular}

\subsection{Numerical simulation of the safety of tailing dam}

In the present research, a finite element method software called ANSYS was selected for data simulation. The tailings dam model based on the dam chosen for the study (see Figure 1) features a height of $22 \mathrm{~m}$, a dam slope of $1.5 \%$, and water elevation in tailings reservoir of $714.25 \mathrm{~m}$.

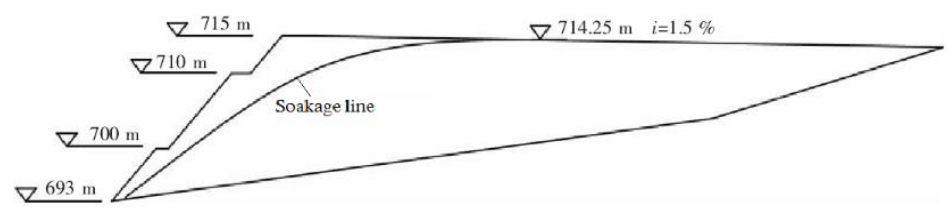

Figure 1 Section diagram of the tailings dam model

\section{$3 \quad$ Results and discussion}

\subsection{Tested results in laboratory}

\subsubsection{The particle size distribution of tailings dam materials}

The particle size distribution of tailings dam materials greatly influences the coefficient of internal friction, permeability coefficient, amount of compression, and the pressure transmission of a tailings dam. The particle size distribution of the tested tailings dam materials is shown in Figure 2, and the measured loose density of tailings dam materials is $1.86 \mathrm{~g} / \mathrm{cm}^{3}$.

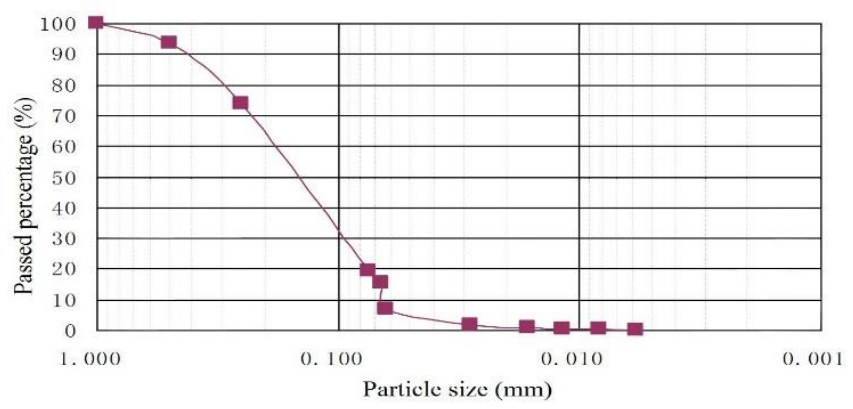

Figure 2 Particle size distribution of tested tailings dam materials

\subsubsection{Static tests}

(1) Relationship between compression and the void ratio of tailings dam materials

In order to study the compression of tailings dam materials, the void ratio of tailings was constantly tested under the reversed cyclic load. The tested compressive curves with different void ratios of tailings dam materials are shown in Figure 3. 


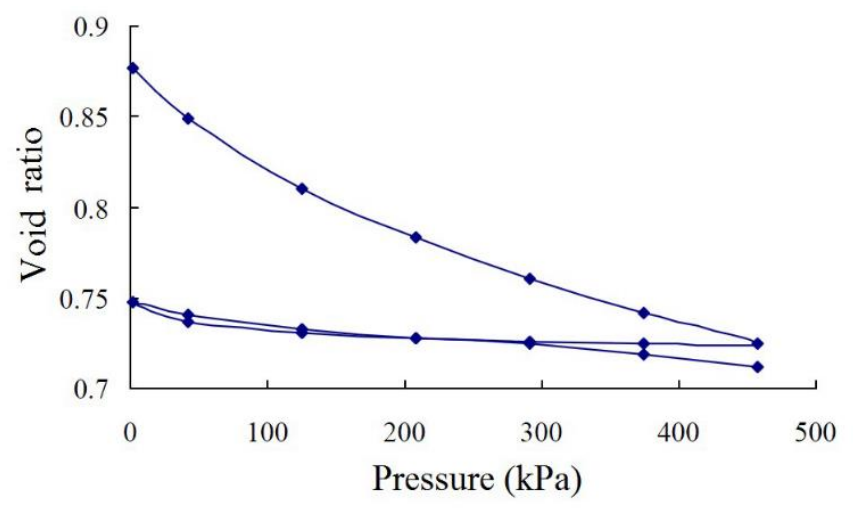

Figure 3 Relationship of compression with void ratio of tailings dam materials

Figure 3 shows that the void ratio of tailings gradually decreases from 0.88 to 0.74 with the regular increase of compressive pressure to $450 \mathrm{kPa}$. However, when the pressure is unloaded, the void ratio recovers to 0.75 , indicating that certain deformation was caused by elastic compression.

(2) Triaxial compression test

By using triaxial tests, the relationship of shear stress with shear strain and the Mohr's circle and related fracturing line of the tested tailings dam materials can be found (see Figure 4).

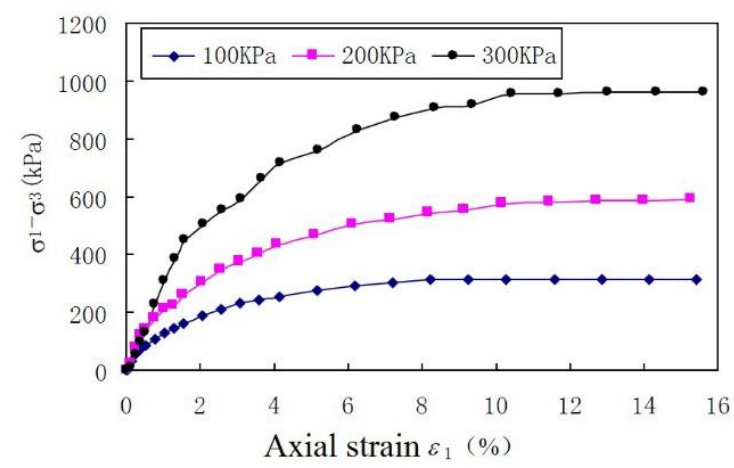

(a)

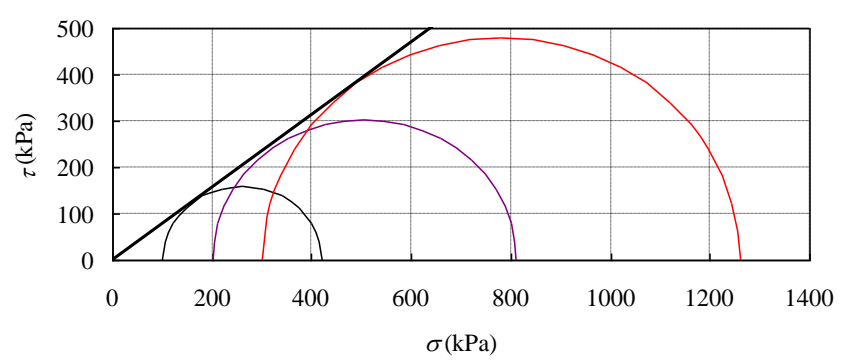

(b)

Figure 4 Triaxial compression tests of tailings dam materials; (a) shear stress-shear strain relationship; (b) Mohr's circle and related fracturing line

Figure 4(a) shows that during the initial stage, the pressure rapidly increases with the axial strain, followed by the tendency towards stability with the growth of axial strain. It is also found that the breakdown pressure increases with the confined pressure. Obviously, when the confined pressure increases from 100 to $300 \mathrm{kPa}$, the breakdown pressure increases to $900 \mathrm{kPa}$. Figure 4(b) shows a lack of cohesion for the tailings. 


\subsubsection{Dynamic strength tests}

The relationship between equivalent vibration times acting on tailings dam and earthquake magnitude is listed in Table 2 (Leger and Javanmardi, 2007; Makdisi and Seed, 1979).

Table 2 Relationship of equivalent vibration times with earthquake magnitude

\begin{tabular}{ccc}
\hline Earthquake magnitude & Equivalent vibration (times) & Lasting time $(\mathbf{s})$ \\
\hline $5.5 \sim 6.0$ & 5 & 8 \\
6.5 & 8 & 14 \\
7.0 & 12 & 20 \\
7.5 & 20 & 40 \\
8.0 & 30 & 60 \\
\hline
\end{tabular}

Figure 5 shows the change of the dynamic shear stress of tested tailings dam materials with that of damage vibration frequency at different confined stresses.

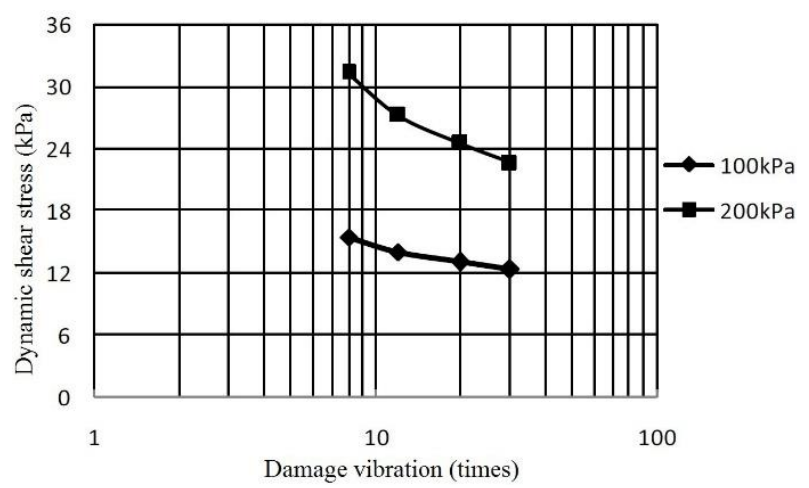

Figure 5 The change of dynamic shear stress with that of the damage vibration frequency of tested tailings dam materials

Figure 5 shows that with the increase of vibration frequency, the dynamic shear stress of tailings dam materials decreases under the same confined pressure, indicating a greater dynamic load of earthquake acting on tailings dam. Hence, the tailing dams are mostly affected with the increase of vibration frequency, hence raising the possibility of liquefy deformation. In addition, the dynamic shear stress of tailings dam materials increases with the growth of confined pressure at the same vibration times.

A typical dynamic stress-strain loop of tested tailings dam materials is shown in Figure 6.

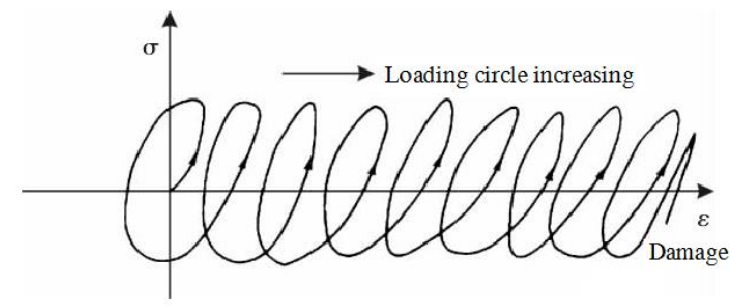

Figure 6 Typical dynamic stress-strain loop of tested tailings dam materials

It could be seen from Figure 6 that with increase of stress, the stress-strain relationship shows an evident inelastic feature, featuring the decrease of elastic modulus while strain increases; during the loading cycle of testing, unrecovered plastic deformation of tailings exists; under the loading cycle, the stress-strain curve of tailings becomes a number of loops similar to the viscous elastic slow-moving one, showing the internal energy consumption of tailings under loading cycles (Sun et al., 2012; Wang et al., 2011; Rico et al., 2008; Liu et al., 2013); if dynamic loading reaches to a certain level, the particle connections of tailings would be completely damaged, hence liquefying the tailings. 
Furthermore, relationship of dynamic stress-strain and the relationship of dynamic modulus-strain can be found in Figure 7.

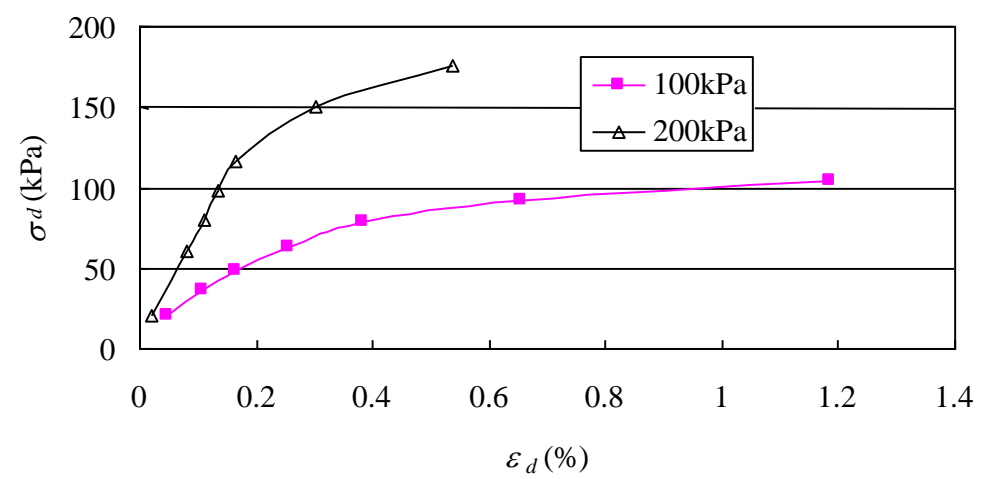

(a)

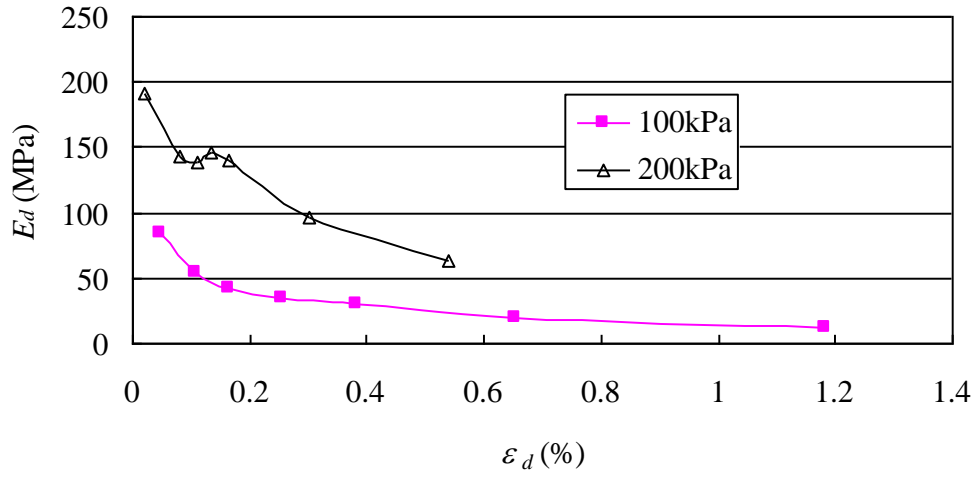

(b)

Figure 7 Dynamic relationship curves of tested tailings dam materials; (a) dynamic stress-strain relationship; (b) dynamic modulus-strain relationship

Figure 7 shows the relationship of dynamic stress-strain at the different confined pressures. It can be seen that the dynamic stress increases with the growth of dynamic strain and features nonlinearity. With the increase of confined pressure, the same value of dynamic strain requires more stress. At the same time, the dynamic modulus of elasticity increases with the growth of side pressure because of the acceleration of the velocity of stress wave and energy when the void ratio of tailings decreases and the relative density increases.

\subsection{Numerical simulation of tailings dam liquefying-damage in earthquakes}

\subsubsection{Simulation parameters}

The physical properties of tailings dam materials used in simulation are listed in Table 3 (also refer back to Figure 1 for the tailings dam model). Parameters of tailings dam materials for static calculation and dynamic calculation are listed in Tables 4 and 5, respectively. The Duncan-Chang model and the Viscous-Elastic model were utilized in static and dynamic simulation respectively.

Table 3 Physical properties of tailings dam materials

\begin{tabular}{ccccc}
\hline Materials & $\begin{array}{c}\text { Permeability } \\
(\mathbf{m} / \mathbf{s})\end{array}$ & Void ratio & $\begin{array}{c}\text { Loose density } \\
(\mathbf{k N} / \mathbf{m})\end{array}$ & $\begin{array}{c}\text { Saturated density } \\
(\mathbf{k N} / \mathbf{m})\end{array}$ \\
\hline Fine tailings & $2.70 \mathrm{E}-5$ & 0.348 & 19.8 & 20.9 \\
Mud tailings & $4.20 \mathrm{E}-5$ & 0.384 & 18.8 & 20.3 \\
Dam base & $2.90 \mathrm{E}-5$ & 0.355 & 20.1 & 21.5 \\
\hline
\end{tabular}


Table 4 Material parameters for static simulation

\begin{tabular}{cccccccc}
\hline \multirow{2}{*}{ Materials } & \multicolumn{3}{c}{ Strength parameters } & \multicolumn{2}{c}{ Young's Modulus } & \multicolumn{2}{c}{ Volume modulus } \\
\cline { 2 - 8 } & $\boldsymbol{\varphi}_{\boldsymbol{0}}$ & $\boldsymbol{\Delta} \boldsymbol{\varphi}_{\boldsymbol{o}}$ & $\boldsymbol{R}_{\boldsymbol{f}}$ & $\boldsymbol{K}$ & $\boldsymbol{n}$ & $\boldsymbol{K}_{\boldsymbol{b}}$ & $\boldsymbol{m}$ \\
\hline Fine tailings & 35.1 & 0.0 & 0.82 & 600 & 0.65 & 460 & 0.32 \\
Mud tailings & 32.4 & 0.0 & 0.62 & 203 & 0.64 & 51 & 0.41 \\
Dam base & 44.2 & 5.0 & 0.77 & 520 & 0.56 & 420 & 0.39 \\
\hline
\end{tabular}

Table 5 Material parameters for dynamic simulation

\begin{tabular}{cccccc}
\hline Materials & $\boldsymbol{k}_{\mathbf{2}}$ & $\boldsymbol{\lambda}_{\max }$ & $\boldsymbol{\mu}_{\boldsymbol{d}}$ & $\boldsymbol{k}_{\boldsymbol{1}}$ & $\boldsymbol{n}$ \\
\hline Fine tailings & 1000 & 23.5 & 0.35 & 10.6 & 0.56 \\
Mud tailings & 460 & 27.0 & 0.48 & 10.4 & 0.70 \\
Dam base & 1200 & 23.3 & 0.35 & 30.4 & 0.61 \\
\hline
\end{tabular}

\subsubsection{Simulated results and discussion}

The simulated deformation vector distribution of tailings dam under the earthquake laoding is shown in Figure 8 , and the simulated liquefied parts and the in situ measured liquefying-damage line of the tailings dam are shown in Figure 9.

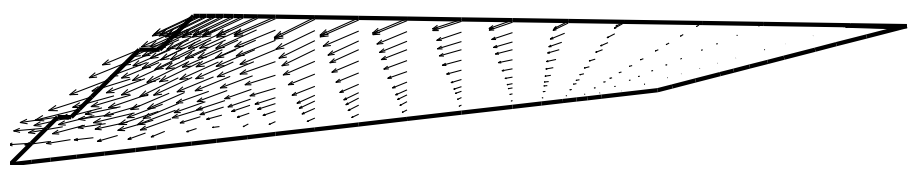

Figure 8 Simulated deformation vector distribution of tailings dam in earthquakes

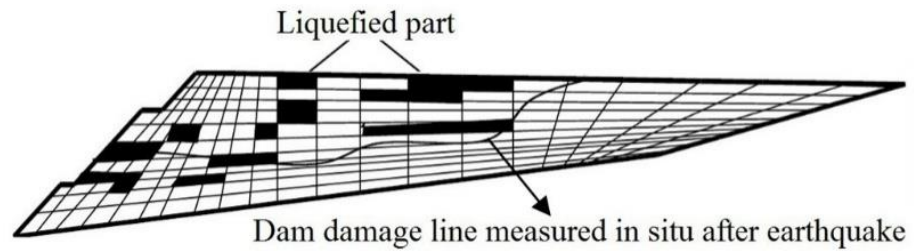

Figure 9 Simulated liquefied parts and in-situ measured liquefying-damage line of the tailings dam

Figure 8 shows the deformation vector caused by earthquakes. With the simulation results capable of predicting the greatest possiblity of liquefication, some preventative measures should be implemented prior to earthpuake. From the Figure 9, liquefied parts which were calculated by numercal simulation occurred in the middle and lower segments, especially the part of high internal hydraulic head. Because the liquefied parts immensely reduced the anti-shear ability of tailings dam materials and subsequently damaged the tailings dam. In addition, the shape of simulated liquefying parts was in good agreement with the actual damaging line measured in situ (as shown in Figure 9). It was proved that the actual factor of dam breaking was weak slip surface formed by the connection of liquefied parts.

\subsection{Factors of safety $(F S)$}

This section discusses how the cyclic resistance ratio (CRR) and the cyclic stress ratio (CSR) influence the safety of tailings dams in earthquakes.

\subsubsection{Influential factors of cyclic resistance ratio (CRR)}

According to the discussion in section 2.1, main factors influencing CRR include the SPT blow count and fine particle content of tailings(FC). The relationships of CRR with those two factors are shown in Figures 10 and 11. 


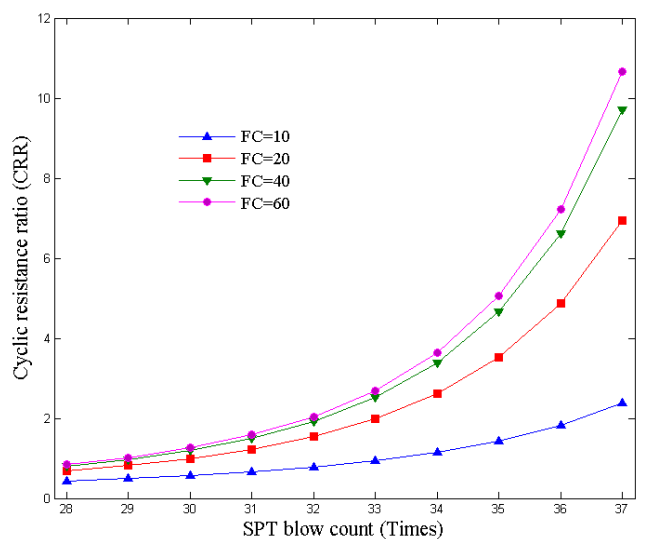

Figure 10 Relationship of $C R R$ with $S P T$ blow count $\left(N_{1}\right)_{60}$ at different fine particle content(FC) of tailings

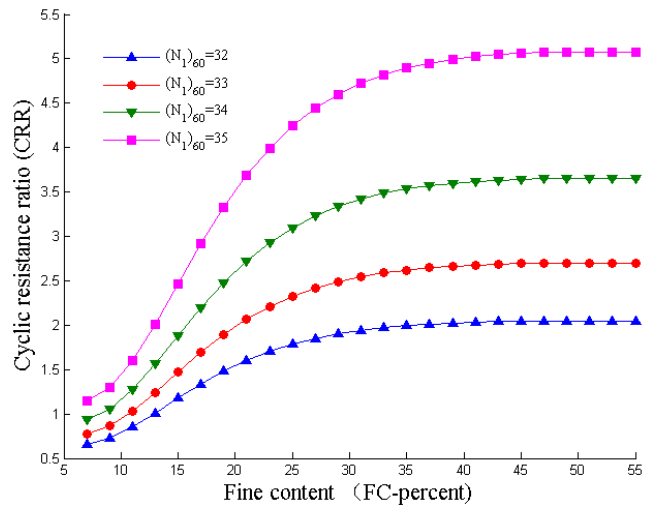

Figure 11 Relationship of $C R R$ with fine particle content(FC) of tailings at different $\left(N_{1}\right)_{60}$

As shown in Figures 10 and 11 , the value of CRR is determined by $\left(\boldsymbol{N}_{\mathbf{1}}\right)_{60}$ and FC value and increases with the growth of $\left(\boldsymbol{N}_{1}\right)_{60}$ value and FC. SPT blow count has little impact on CRR value when the FC value is small, and with the growth of FC, CRR increases rapidly at the initial phase, but it almost keeps constant when the percentage value of $\mathrm{FC}$ augments sequentially.

\subsubsection{Factors influencing the cyclic stress ratio (CSR)}

CSR is the average level of shear stress exerted on the ground by earthquake loading at a certain depth. Its value is determined by the stress reduction coefficient, depth below ground surface, earthquake magnitude, SPT blow count and other parameters measured in situ.

(1) Stress reduction coefficient, $\gamma_{d}$

According the Equation (3) above, stress reduction coefficient related to the earthquake magnitude and the depth below ground surface is an important parameter for the prediction of the value of CSR. It changes with the depth below ground surface at different earthquake magnitude as shown in Figure 12. 


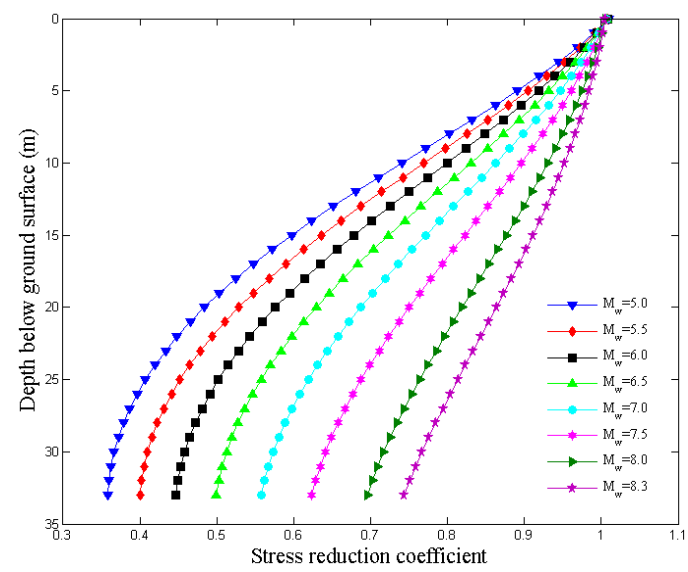

\section{Figure 12 Relationship of stress reduction coefficient with depth at different earthquake magnitude}

Plots of $\gamma_{d}$ calculated using Equation (3a) for $\mathrm{M}_{\mathrm{w}}=5.0 \sim 8.3$ are presented in Figure 12, which indicates that the value of $\gamma_{d}$ decreases with the reduction of depth and earthquake magnitude.

(2) The factors influencing CSR

The relationships of CSR and SPT below count, depth, and earthquake magnitude are shown in Figures 13 and 14 .

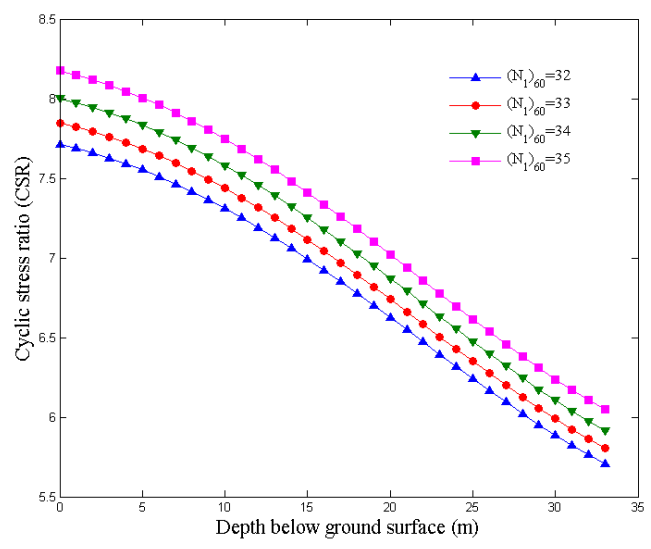

Figure 13 Relationships of cyclic stress ratio with depth at different SPT blow count

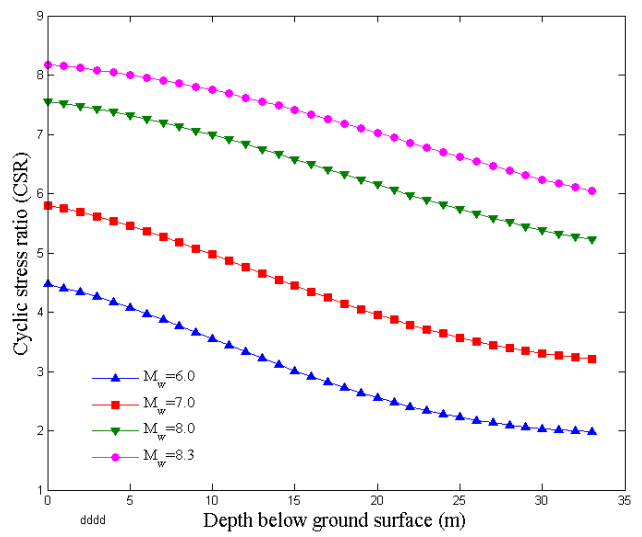

Figure 14 Relationships of cyclic stress ratio with depth at different earthquake magnitude

It could be found that the value of CSR decreases with the increase of depth below dam surface and increases with the increase of SPT below count and earthquake magnitude, but the earthquake magnitude exerts a greater impact than SPT below count. 


\subsubsection{Influential factors of safety (FS)}

The relationships of FS with such main factors as percentage of fine particle content (FC), SPT below count, peak horizontal acceleration, earthquake magnitude and depth below dam surface are shown in Figure 15.

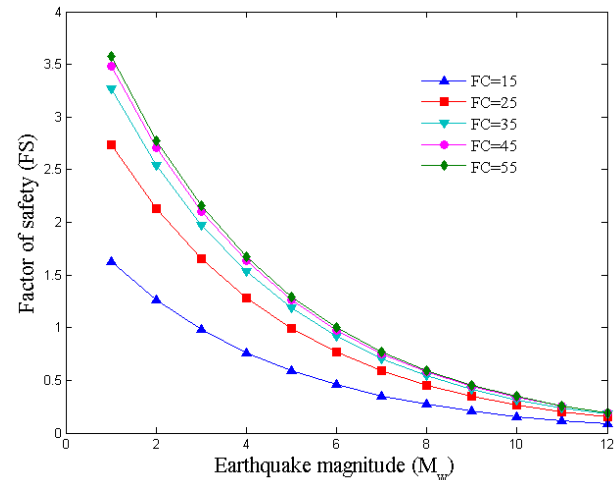

(a)

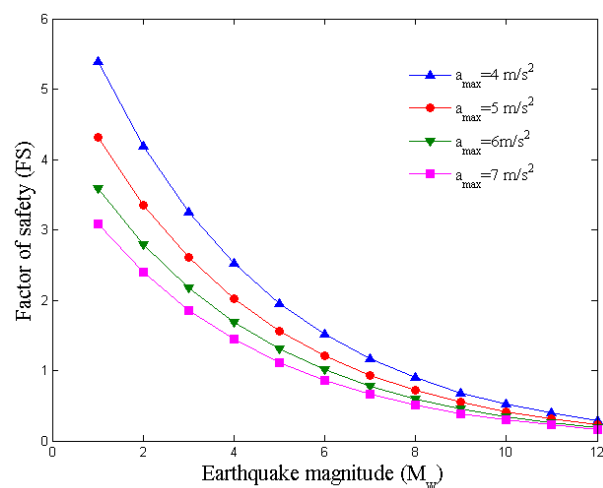

(c)

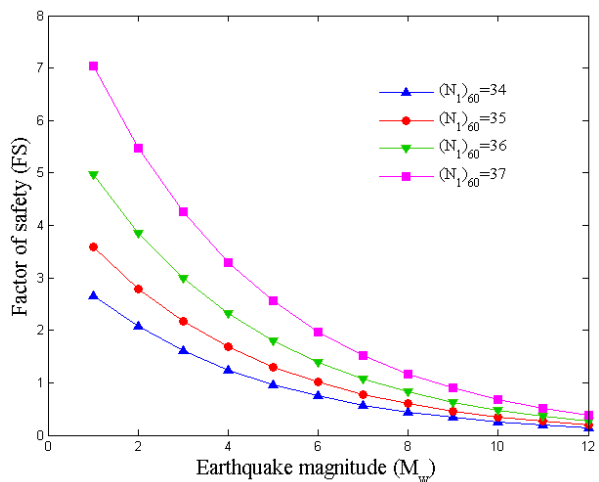

(b)

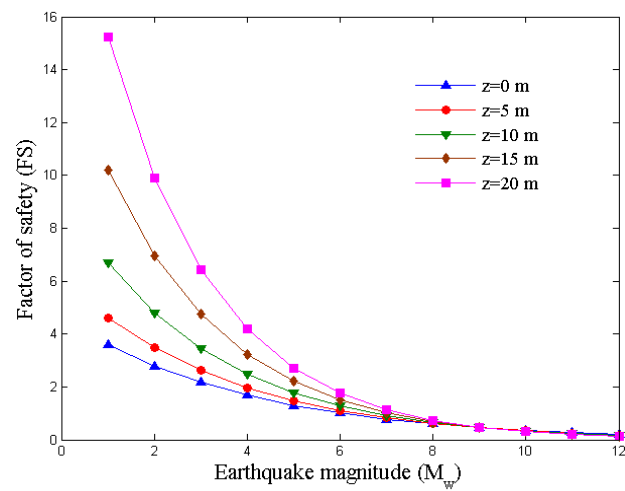

(d)

Figure 15 Relationships of factors of safety with earthquake magnitude; (a) percentage of fine particle content (FC); (b) SPT below count; (c) peak horizontal acceleration; (d) depth below dam surface

The plots of Figure 15 shows that FS decreases rapidly with the increase of earthquake magnitude. Among them, Figure 15(a) shows the influence of FC on FS, Figure 15(b) the count of SPT on FS, Figure 15(c) the growth of peak horizontal acceleration on FS and Figure 15(d) the influence of different depth on FS when earthquake magnitude is smaller than 7. However, some other factors would also affect FS and thus cannot be neglected.

A number of researchers (Wu et al., 2011; Wang et al., 2015) have pointed out that for paste tailings disposal on surface, because of the low water content, the FS of paste tailings dam would be much higher, as shown in Figure 16. 


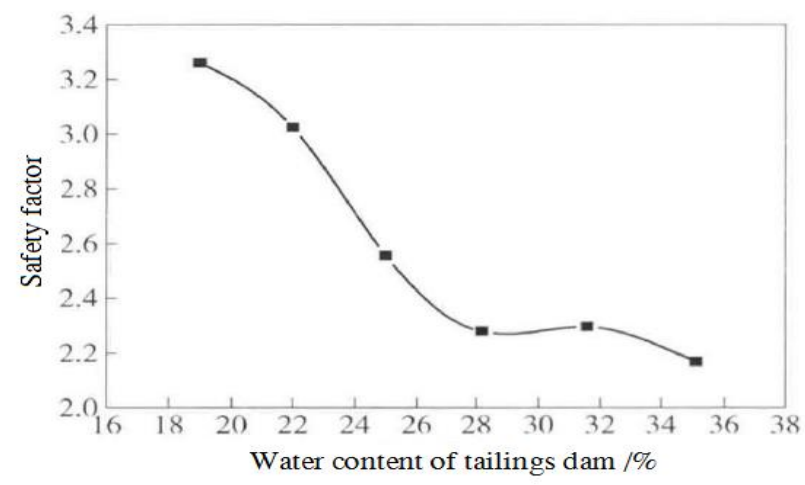

Figure 16 Relationship of safety factor with water content of tailings dam mterials (Yang and Ai, 2013)

\section{Conclusions}

As a special geo-structure, mine tailings dams could be easily liquefied and damaged under dynamic load of a violent earthquake. In this paper, the process of tailings dam liquefying-damage during earthquakes was studied by the use of the ANSYS software was used for numerical simulation as well as the establishment of a mechanical model that takes into account the earthquake magnitude, tailings dam safety factor and critical shear strain causing liquefaction.

The simulated results showed that for tailings dams, parts such as sections at both sides of the soakage line, the top section close to water surface and so on are particularly prone to liquefaction and damage, which is in a good agreement with the measured data in field.

For the safety purpose of tailings disposal of those mines located in areas subjected to frequent earthquakes, paste tailings disposal would be a reasonable choice.

\section{References}

Franks, D. and Boger, D. 2011, 'Sustainable development principles for the disposal of mining and mineral processing wastes', Resources Policy, vol. 36, no. 2, pp. 114-122.

Leger, P. and Javanmardi, F. 2007, 'Seismic stability of concrete gravity dams strengthened by rockfill buttressing', Soil Dynamics and Earthquake Engineering, vol. 27, no. 3, pp. 274-290.

Liu, J.P., Feng, X.T. and Li, Y.H. 2013, 'Studies on temporal and spatial variation of microseismic activities in a deep metal mine', International Journal of Rock Mechanics and Mining Sciences, no. 60, pp. 171-179.

Makdisi, F. and Seed, H. 1979, 'Simplified Procedure for Evaluating Embankment Response', Geotechnical Eng. Div., Proceeding of ASCE, no. GT12, pp. 105-110.

Pu, H. and Zhang, J. 2012, 'Research on protecting the safety of buildings by using backfill mining with solid', Procedia Environmental Sciences, no. 12, pp. 191-198.

Rico, M., Benito, G. and Diez, H.A. 2008, 'Floods from tailings dam failures', Journal of Hazardous Materials, vol. 154, no. 1, pp. 79-87.

Robertson, P.K. and Wride, C.E. 1998, 'Evaluating cyclic liquefaction potential using the cone penetration test', Canadian Geotechnical Journal, vol. 35, no. 3, pp. 443-459.

Sun, E.J., Zhang, X.K. and Li, Z.X. 2012, 'The internet of things (IOT) and cloud computing (CC) based tailings dam monitoring and prealarm system in mines', Safety Science, vol. 50, no. 4, pp. 811-815.

Wang, J.D., Wu, A.X., Wang, Y.M., Wang, H.J. and Wang, Y. 2015, 'Co-disposal technology reconstruction of paste backfilling and tailings discharge in a gold mine', Metal Mine, no. 11, pp. 12-16. 
Wang, T., Zhou, Y. and Lv, Q. 2011, 'A safety assessment of the new Xiangyun phosphogypsum tailings pond', Minerals Engineering, vol. 24, no. 10, pp. 1084-1090.

Wang, Y.Z., Zhu, J.J., Ou, Z.Q., Li, Z.W. and Xing, X.M. 2012, 'Coseismic slip distribution of 2009 L'Aquila earthquake derived from InSAR and GPS data', Journal of Central South University, no.19, pp. 244-251.

Wu, A.X., Yang, S.K., Wang, H.J., Jiang, H.Z. and Xiao, Y.T. 2011, 'Current status and development trend of paste extre-fine total tailings disposal technique', Mining Technology, vol. 11, no. 3, pp. 4-8.

Yang, L.Y. and Ai, C.M. 2013, 'Dam stability analysis of tailing paste stockpiling in a Chinese mine', China Mine Engineering, vol. 42 , no. 6, pp. 67-71.

Zhang, D., Wu, Z.Z. and Cai, S.J. 2010, 'Discussion on tailings reservoir dam failure risk assessment index system under seismic conditions', Journal of safety Science and Technology, vol. 6, no. 6, pp. 17-22.

Zhang, G., Robertson, P.K. and Brachman, R.W.I. 2002, 'Estimating liquefaction-induced ground settlements from CPT for level ground', Canadian Geotechnical Journal, vol. 39, no. 5, pp. 1168-1180.

Zhang, Q., Zhang, J.X., Huang, Y.L. and Ju, F. 2012, 'Backfilling technology and strata behaviors in fully mechanized coal mining working face', International Journal of Mining Science and Technology, vol. 22, no. 2, pp. 151-157. 